\title{
Numerical Simulation of lateral dike breaching due to overtopping
}

\author{
Benjamin Dewals ${ }^{1}$, Ismail Rifai ${ }^{1,2}$, Kamal El-Kadi Abderrazek ${ }^{2}$, Massimo Greco ${ }^{3}$, Cristiana \\ Di Cristo ${ }^{4}$, Michele Iervolino ${ }^{5}$, Angelo Leopardi ${ }^{4,1}$, and Andrea Vacca $^{3}$ \\ ${ }^{1}$ HECE - University of Liège, Liègem Belgium \\ ${ }^{2}$ EDF R\&D and Saint-Venant Laboratory for Hydraulics, Chatou, France \\ ${ }^{3}$ DICEA - University of Napoli "Federico II", Napoli, Italy \\ ${ }^{4}$ DICeM - University of Cassino and Southern Lazio, Cassino (FR), Italy \\ ${ }^{5}$ DI - Università della Campania "Vanvitelli", Aversa (CE), Italy
}

\begin{abstract}
Dikes and levees are encountered very often along rivers. They are crucial as defence structures for flow channelization, protecting population and properties from floods as well as against lateral riverbed migration. However, the combination of their aging and increased exposition to extreme hydrological events may cause these structures to breach, and subsequently to fail. Understanding the dynamics of breaching is very important for developing adequate countermeasures, for civil protection initiatives and for land use planning. Recent literature shows many studies concerning, both from experimental and numerical point of views, frontal dike breaching. Based on several evidences, it is well assessed that depth-integrated numerical models can successfully reproduce this kind of phenomenon (e.g. Greco et al., 2012). Recently, Rifai et al. (2017) investigated a different setup in which the embankment is parallel to the main channel flow and thus a lateral breaching occurs. It is worth noting this scheme resembles real-world situation of levees breaching along a river. In present paper, the capability of depth-integrated approaches in reproducing such tests is investigated. Numerical results obtained with different models are compared against experiments from both the qualitative and quantitative point of views. Considerations about the applicability of depth-integrated models in real world situation of lateral breaching of dikes and levees are also drawn.
\end{abstract}

\section{Introduction}

Earth dikes or levees constitute a key element in the protection of riverine areas from inundation. Designed to defend the floodplain areas, they may unwantedly turn into a source of hazard whenever a failure occurs. Among the different causes of failure, the overtopping is responsible of about 35\% of earth dam failures (Costa 1985; Vorogushyn et al. 2010; Fry et al. 2012). Once overtopping has occurred, the flow passing over the top of the levee triggers an intense erosive process and the rapid growth of a breach, whose progressive enlargement exacerbates the flow of floodwaters over the formerly protected riverine areas. For this

\footnotetext{
${ }^{1}$ Corresponding author: a.leopardi@unicas.it
} 
reason, the investigation of dynamics and consequences of levee overtopping is of utmost interest for fluvial risk analysis.

The occurrence of overtopping is supposed to increase in the future, as a product of the intensification of the hydrological forcing due to climate change, and of the natural levee obsolescence, sometimes exacerbated by lack of maintenance, inadequate rehabilitation works (e.g., grass cover and tree roots poorly managed) or even by interaction with wildlife.

Several efforts have been devoted worldwide to improve the detection of potential failure points along leveed rivers. To cite two examples, the Levee Safety Program created by the USACE in 2006 and the 2004 campaign by the FEMA (Morrissey 2006), under the Flood Map Modernization Initiative (Map Mod). The outcome of similar initiatives is a ranking of existing structures accordingly to their exposition to the occurrence of failures. The subsequent step in a proper risk management strategy is to try to forecast the exposition of riverside areas and properties to the consequences of a levee failure and the possible countermeasures.

Unfortunately, the detailed picture of the physical processes occurring during levee overtopping is still incomplete. Descriptive models are often based on purely empirical observation, and predictive ones, to date, appear far from being adequately reliable. Indeed, hydrodynamics may likely exhibits three-dimensional flow patterns, but the need for application to field-scale scenarios of risk assessment discourages the application of threedimensional models, and indicates two-dimensional depth-averaged ones as a reasonable trade-off between detail of the description and computational efforts. Moreover, sediment transport and morphology evolve with timescales comparable to that of hydrodynamics (leading to a fast geomorphic transient), an additionally and mass failure and slumps occur during the breach evolution.

Despite consistent research efforts are still needed, some advancements have been recently reported concerning both the physical and mathematical modelling of levee overtopping. As far as the former is concerned, most of the previous experimental research has dealt with the case of frontal overtopping (e.g. Schmoker and Hager, 2009), i.e. not considering the streamwise flow between the riverbanks, which is, however, an essential feature in a realistic leveed river flow. With the aim to bridge this gap, Rifai et al. (2017) investigated a setup in which the embankment is parallel to the main channel flow and thus a lateral breaching occurs, providing a detailed dataset of laboratory experiments of levee breaching.

As far as the mathematical modelling of lateral breaching is concerned, several isolated elements of the complete process have been recently improved, but complete analyses are scarcely reported. Two-layer, mixture and two-phase models are available for the numerical simulation of the sediment transport under rapid transients. Among many others, the papers by $\mathrm{Wu}$ and Wang (2007), Swartenbroekx et al. (2013) and Dewals et al. (2011) provide a representative picture of the peculiarities of each category. Belonging to the last one, the paper by Pontillo et al. (2010) successfully compares experimental and simulated evolution of earth dam erosion by frontal overtopping.

On the other hand, to account for the occurrence of mass failures, several geofailure operators have been proposed (e.g.: Cao et al. 2011; Guan et al. 2014; Volz et al. 2012; Swartenbroekx et al. 2010). Di Cristo et al. (2017) have recently discussed the integration of a novel geofailure operator (Evangelista et al. 2015) with a two-phase model for fast geomorphic transients (Di Cristo et al. 2016). The resulting model successfully reproduced the impact of a dam-break wave on an erodible embankment with a steep slope compared with laboratory experiments. The geofailure operator demonstrated to be mandatory in presence of bottom slopes close to the friction angle of the sediment. 
In present paper, the numerical simulation of the Run 8 of the experimental campaign by Rifai et al. (2017) is presented, as well as some considerations about applicability of 2D depth-integrated approach in such situations.

Two models are considered: the first is the two-phase one proposed in Di Cristo et al. (2016), that includes a geofailure operator in order to account for slope failures; the second is obtained from the well known Telemac-Mascaret numerical suite, coupling the 2D depthintegrated module Telemac2D with the sediment transport and bed evolution module Sisyphe.

\section{The Numerical Model}

\section{The Morphodynamical model}

The two-phase morphodynamical model with geofailure operator considered in the present simulation is the one described by Di Cristo et al. (2016). The reader is referred to that paper for a detailed review of the model assumptions/limitations, and for the description of the numerical method employed for the simulations, whereas only a brief outline is given in the following. Neglecting, as in the present application, the suspended load, the model is constituted by the equations expressing the mass and momentum conservation for the liquid and the solid phase transported as bed load. The evolution of the erodible bottom is described by means of an ordinary differential equation involving an erosion/deposition operator. The source terms of the momentum equations describe the effects of shear stress, attrition, particle collision and drag exchange between liquid and solid phase. Their expression is reported in Di Cristo et al. (2016), where it is also shown that with a suitable set of closures the model reproduces, under steady uniform conditions of flow, the well-known Meyer-Peter and Muller sediment transport formula. The set of closures depends on three independent dimensionless parameters. Two of them, characterizing the shear stress and the sediment transport concentration under uniform flow, may be estimated based on common practice. The remaining free model parameter is defined between a lower and an upper bound and has a limited sensitivity on the results.

\section{The results}

The simulations have been carried out over a non-structured mesh of 16125 rectangular elements and with a timestep $\Delta t=1 / 1024 \mathrm{~s}$. All the sediment properties were given the values reported in Rifai et al. (2017). Additionally, the dynamic friction angle was assumed as $25^{\circ}$ and the repose angle of the unsaturated sand as $87.5^{\circ}$. The dimensionless Chezy coefficient was given the customary value $C_{C h}=19$, the concentration parameter was assumed as 1.3 , whereas the free parameter was given the value $c_{1}=0.15$ as in Di Cristo et al. (2016).

Figure 1 reports the simulated bottom topography at three times during the breach evolution (the experimental run lasts about $780 \mathrm{~s}$ ). As it can be observed, after $90 \mathrm{~s}$ the portion of the levee corresponding to the initial notch position $(x=6.15 \mathrm{~m})$ has been completely removed, thus revealing the underlying non-erodible bottom. At $t=210 \mathrm{~s}$, the breach has slightly widened both in the downstream and the upstream direction of the in-bank flow, but a substantial reshaping has occurred. The upstream trunk of the breached levee has a triangular shape, whereas the downstream one is characterized by a straight upstream-looking face, forming an angle of about $60^{\circ}$ respect to the $x$ axis. The breach continues widening both in the upstream and in the downstream direction up to the end of the run $(t=600 \mathrm{~s})$, essentially conserving the same shape. 

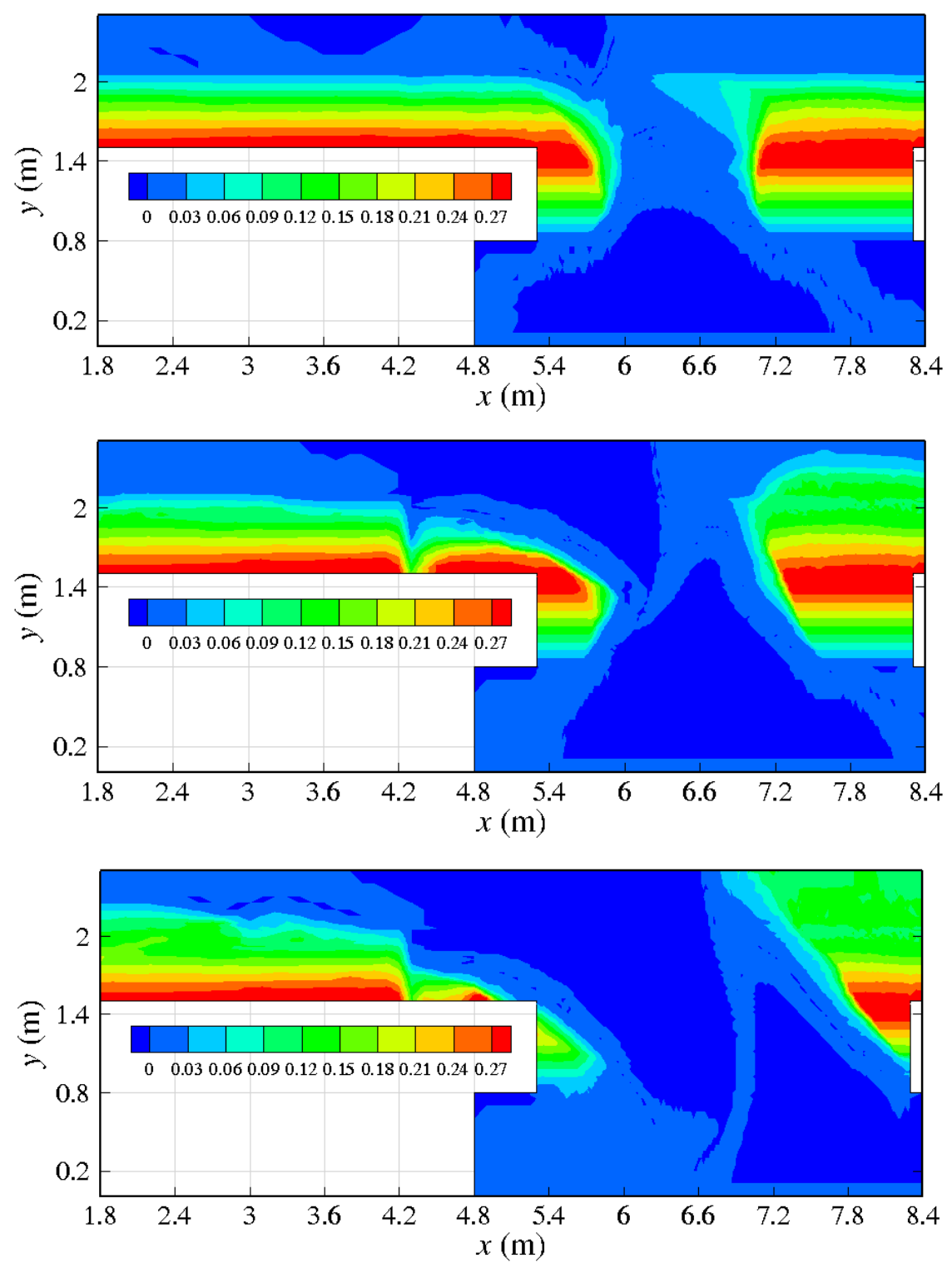

Figure 1 - Bottom evolution computed with the two-phase morphological model by Di Cristo et al. (2016) at $t=90 \mathrm{~s}, 210 \mathrm{~s}, 600 \mathrm{~s}$.

The comparison with the close-up three dimensional views based on the experiments of Rifai et al. (2017) shows that the main features of the simulated breach evolution generally complies with the experimental observation. However, two major differences are apparent.: the upstream-looking face of the downstream trunk of the levee maintains in the experiment perpendicular to the in-bank flow direction, and the breach widening is sensibly more pronounced in the downstream direction than in the upstream one. 

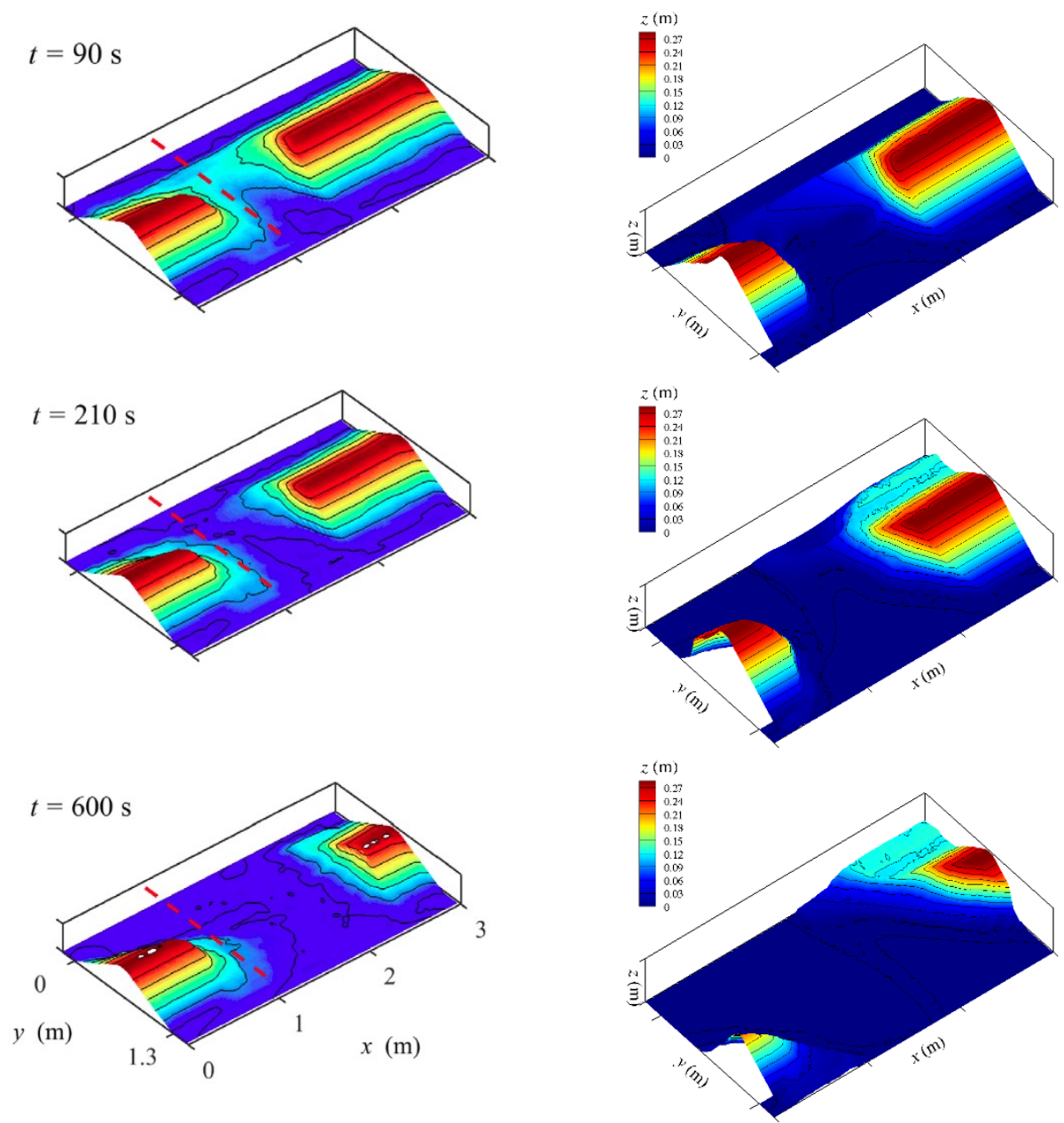

Figure 2 - Bottom evolution computed with the two-phase morphological model by Di Cristo et al. (2016) at $t=90 \mathrm{~s}, 210 \mathrm{~s}, 600 \mathrm{~s}$ (right) compared against experimental results by Rifai et al. (2017)

\section{Numerical Simulation with the Telemac-Mascaret numerical suite}

\section{The OpenTelemac numerical suite}

The OpenTelemac (Telemac-Mascaret) suite is chosen as numerical modelling framework (Hervouet, 2007). The 2D depth-integrated shallow water module Telemac2D coupled with the sediment transport and bed evolution one, Sisyphe, is adopted for the numerical reproduction of the experimental results by Rifai et Al. (2017). A time step of $0.01 \mathrm{~s}$ is assumed in the computation. The coupling time step is the same as the computation one, i.e. the coupling between the hydrodynamic and the sediment transport modules is considered in each time step.

In the hydrodynamic model the k- $\varepsilon$ turbulence model was used for the lateral stresses reproduction, in which the classical parameters were assumed (Launder and Sharma, 1974). 
For the bed load-transport the Meyer-Peter and Muller formula is adopted, while the possibility of slope failure is considered by means of the slope failure operator available in OpenTelemac (Rousseau et Al., 2014), assuming a sediment friction angle equal to $43^{\circ}$.

It was verified that this latter modelling approach is fundamental, since without the slope failure operator the dynamic of the breach opening is totally missed.

\section{The results}

The computation was performed on a triangular mesh with 18392 elements. In Figure 3 bottom evolution after $90 \mathrm{~s}, 210 \mathrm{~s}$ and $600 \mathrm{~s}$ after the breach triggering are presented.

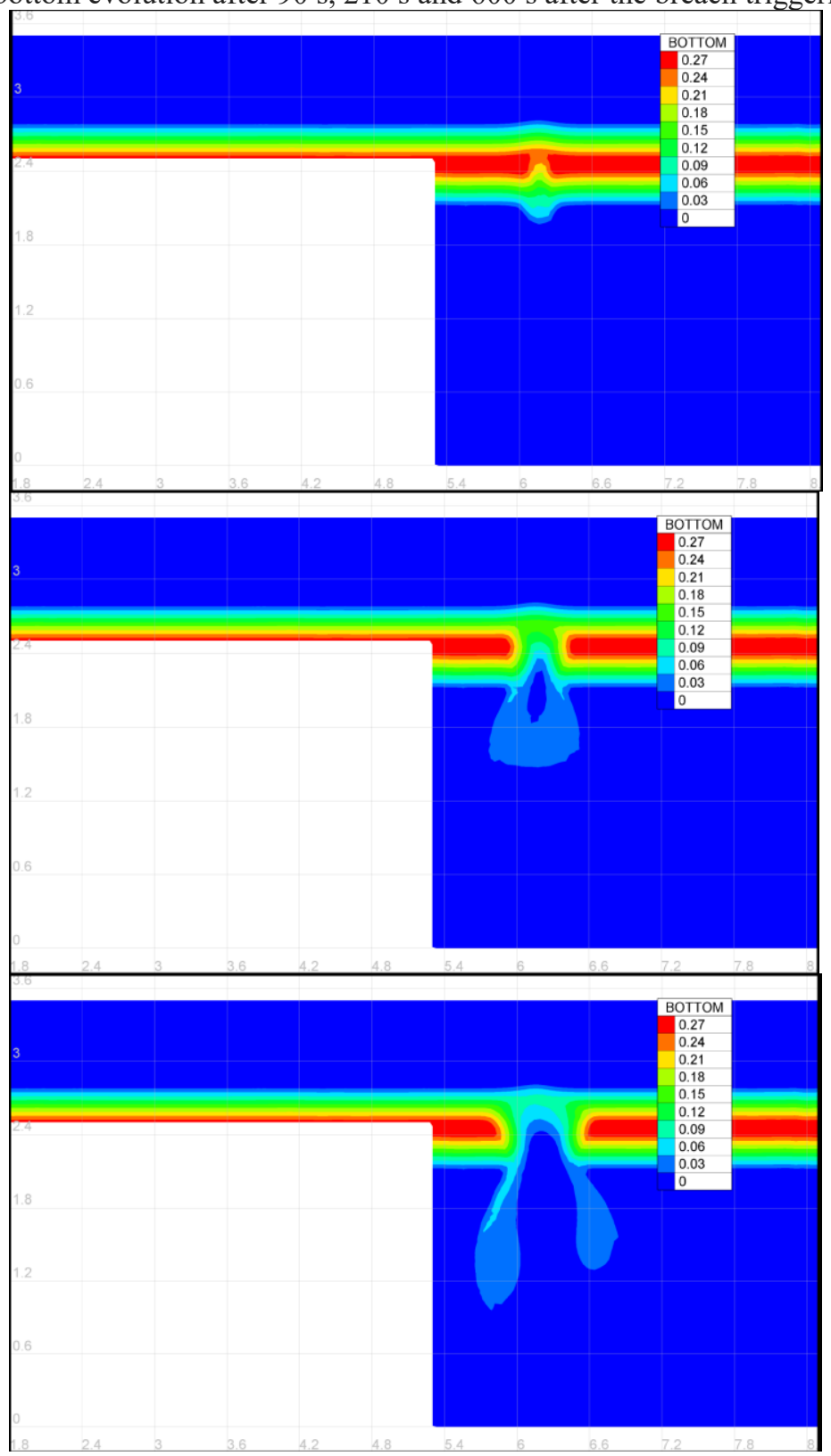

Figure 3 - Bottom evolution computed with Telemac2D - Sisyphe at t $=90$ s, 210 s, $600 \mathrm{~s}$. 

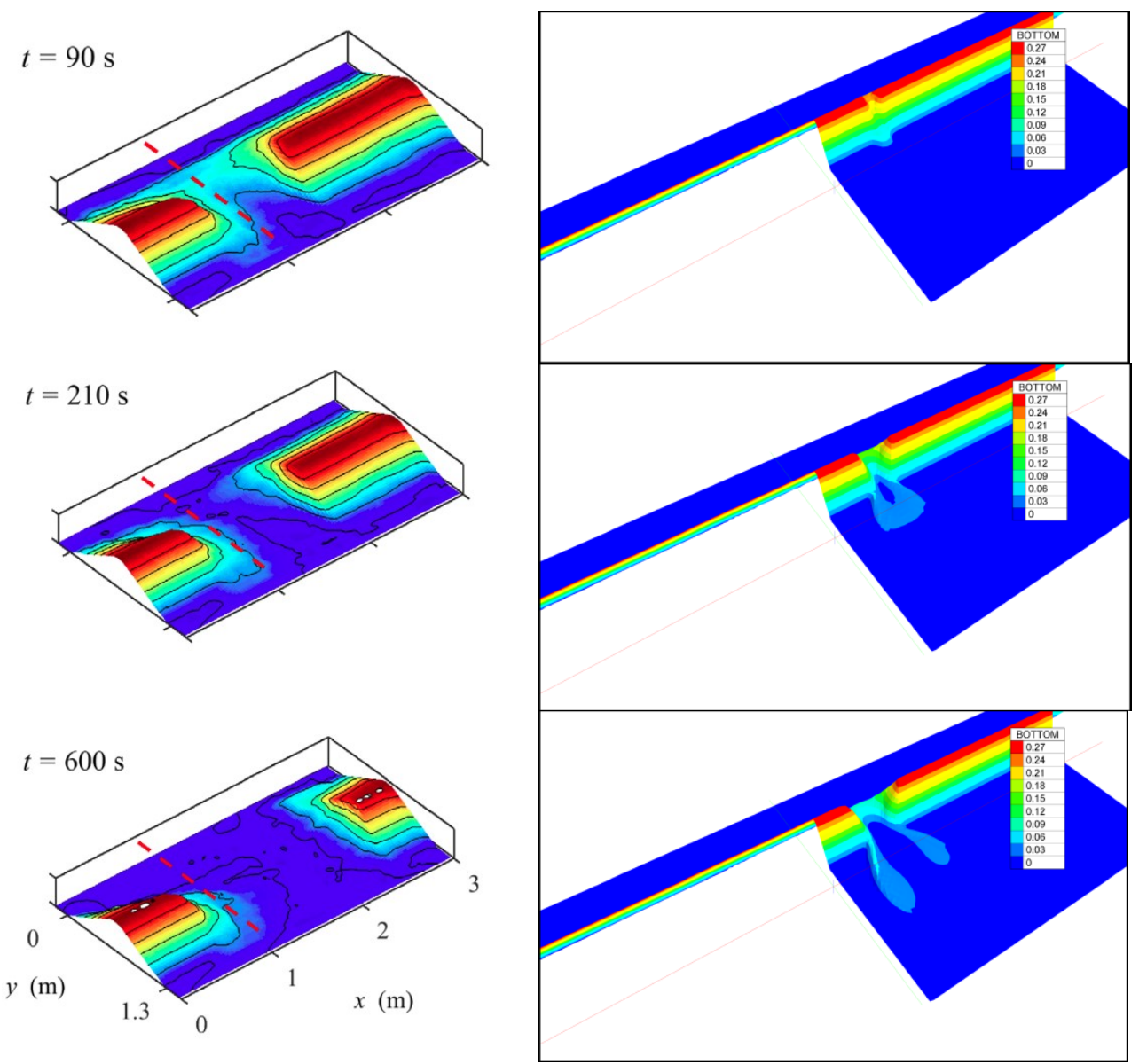

Figure 4 - Bottom evolution computed with Telemac2D - Sisyphe at t $=90 \mathrm{~s}, 210 \mathrm{~s}, 600 \mathrm{~s}$ (right) compared against experimental results by Rifai et al.

The initial position of the breach is at $x=6.15 \mathrm{~m}$. Comparing numerical results against experimental ones, it is worth noting the computed evolution of the breach is characterized by a similar dimension but with an important difference: in experiments the breach evolves in the direction of the flow, while in the numerical simulations the breach widening is substantially symmetrical in regard to its initial position. At the end of the process two-tongue deposition shape is obtained from the computation, that is not observed in experiments.

Such behaviour, common to both the mathematical models considered, could be due to some 3D features of the flow field (Michelazzo, 2014), and it will be investigated in future works.

\section{Conclusions and future developments}

In present paper the numerical simulation of one of the experiment by Rifai et al. (2017) is performed. The setup is characterized by a geometry in which the embankment is parallel to the main channel flow and thus a lateral breaching occurs. Two models are employed: the two-phase one proposed by Di Cristo et al. (2016) and the customary OpenTelemac in a 2D depth integrated framework.

Both models are able to qualitatively predict the widening of the breach, but its evolution is not correctly reproduced from the quantitative point of view: while in the simulation the 
evolution of the breach in the streamwise direction is almost symmetrical with respect to the initial notch location, in the experiments a downstream migration of the breach is observed. It is conjectured that such a behaviour could be due to some 3D features of the flow field, which have been experimentally detected on similar geometries (Michelazzo, 2014). This aspect will be deeply investigated in further analysis.

\section{References}

1. Z. Cao, Z. Yue, G. Pender. Nat. Haz. 59, 2, 1021 (2011)

2. J. E. Costa, Floods from dam failures, USGS Rep., 85-560, 54 (1985)

3. C. Di Cristo, S. Evangelista, M. Greco, M. Iervolino, A. Leopardi, A. Vacca, J. Hydr. Res. (2017)

4. B. Dewals, F. Rulot, S. Erpicum, P. Archambeau, M. Pirotton, Advanced topics in sediment transport modelling: non-alluvial beds and hyperconcentrated flows, sediment transport (Intech, 2011)

5. C. Di Cristo, M. Greco, M. Iervolino, A. Leopardi, A. Vacca, J. Hydr. Engrg. 142, 2, 04015043 (2016)

6. S. Evangelista, M. Greco, M. Iervolino, A. Leopardi, A. Vacca, Int. J. Sed. Res. 30, 4, $382(2015)$

7. J. Fry, A. Vogel, P. Royet, J. Courivaud, 6th International Conference on Scour and Erosion (Paris, 2012)

8. M. Greco, M. Iervolino, A. Leopardi, A. Vacca, Int. J. Sed. Res., 27, 4, 409 (2012)

9. M. Guan, N.G. Wright, P.A. Sleigh, J. Hydr. Engrg. 140, 7, 040140221 (2014)

10. J.-M. Hervouet, Hydrodynamics of Free Surface Flows: Modelling with the Finite Element Method (Wiley, 2007)

11. B.E. Launder and B.I. Sharma, B. I. Letters in Heat and Mass Transfer, 1, 2, 131-138. (1974)

12. G Michelazzo, Breaching of river levees: analytical flow modelling and experimental hydro-morphodynamic investigations ( $\mathrm{PhD}$ thesis, Univ. of Florence, Italy 2014),

13. W.A. Morrissey, FEMA's Flood Hazard Map Modernization Initiative, CRS Report for Congress (Washington, DC, 2006)

14. M. Pontillo, L. Schmocker, M. Greco, W.H Hager, J. Hydr. Res. 48, 5, 573 (2010)

15. I. Rifai, S. Erpicum, P. Archambeau, D. Violeau, M. Pirotton, K. El Kadi Abderrezzak, B. Dewals, Water Resour. Res. 53, 3373 (2017)

16. Rosseau Y.Y., van de Wiel M.J., Biron P.M., Int. Conf. RiverFlow 2014 (2014)

17. L. Schmocker, W.H. Hager, J. Hydraulic Res. 47, 5, 585 (2009)

18. C. Swartenbroekx, S. Soares Frazão, R. Staquet, Y. Zech, J. Hydr. Res. 48, 3, 302 (2010)

19. C. Swartenbroekx, Y. Zech, S. Soares Frazão, Int. J. Num. Meth. Fluids, 73, 5, 477 (2013)

20. C. Volz, P. Rousselot, D. Vetch, R. Faeh, J. of Hydr. Res. 50, 6, 587 (2012)

21. S. Vorogushyn, B. Merz, K.E. Lindenschmidt, H. Apel, Water Resour. Res. 46, W08541 (2010)

22. W. Wu, S. S.-Y. Wang, J. Hydr. Engrg. 133, 1, 48 (2007) 